\title{
Global Cities and Local Challenges: Booms and Busts in the London Real Estate Market
}

\author{
Alessandra Canepa $^{1,2} \cdot$ Emilio Zanetti Chini $^{3} \cdot$ Huthaifa Alqaralleh $^{4}$
}

Accepted: 26 October 2020 /Published online: 5 November 2020

(C) The Author(s) 2020

\begin{abstract}
In this paper we investigate the dynamic features of house prices in London. Using a generalized smooth transition model (GSTAR) we show that dynamic symmetry in price cycles in the London housing market is strongly rejected. We also show that the GSTAR model is able to replicate the features of the observed cycle in the simulated data. Further, our results show that the proposed model performs well when compared to other linear and nonlinear specifications in a out-of-sample forecasting exercise.
\end{abstract}

Keywords House price cycles $\cdot$ Dynamic asymmetries $\cdot$ Nonlinear models $\cdot$ Forecasting

JEL Classification $\mathrm{C} 10 \cdot \mathrm{C} 31 \cdot \mathrm{C} 33$

\section{Introduction}

During the last few decades economic systems have been characterized by a high degree of globalization. The literature on urban studies supports the view that the process of internationalization in financial and service sectors has created "global cities" or world cities (see, for example, Sassen 1991; Dehesh and Pugh 2000). These cities are "global hubs" which are instrumental in supporting the operation of the global financial and trade systems.

The city of London has long been considered a global metropolis (see for example Sassen 2003). London's influence today draws on the city's long-standing status as a centre of international power, first as a trading centre then as an imperial capital. The

\footnotetext{
Alessandra Canepa

Alessandra.Canepa@unito.it

Emilio Zanetti Chini

emilio.zanettichini@uniroma1.it

Huthaifa Alqaralleh

huthaifa89@mutah.edu.jo
}

Extended author information available on the last page of the article 
globalization process was enhanced in the 1980s by the deregulation of the financial market promoted by the Prime Minister Margaret Thatcher which re-consolidated London as a world class financial centre. After the 1980s the supremacy of the city as global financial centre has been unchallenged. In this respect, the city of London was consistently ranked at the Global Financial Centres Index (GFCI) in the last ten years. ${ }^{1}$ Moreover, the city also constitutes an important innovation hub, it hosts high quality educational institutions and features high degree cultural diversity. In this respect, the city of London was ranked at the top of the Global Power City Index (GPCI) in 2019 and it was in the same position for the last few years in a row. ${ }^{2}$

The positive agglomeration effects in the productive sphere and the global city status that London enjoys, have taken their toll in the cost of housing. In the literature, dedicated empirical studies of the dynamics of housing markets in global cities are still rare. However theoretical works support the view that housing market cycles in large metropolitan areas feature asymmetric behaviour. Consensus literature shares in common that in densely populated urban areas the rigidity of the supply side plays a major role in housing market cycles. According to this line of research the high real cost of construction and strict regulations on new developments introduce unpriced supply restrictions. For instance, Capozza et al. (2004) show that stricter regulations on new development such as minimum lot size, or regulatory-induced delays increase the cost of new housing (both in absolute terms and in relation to existing housing) and reduce the ability of builders to respond quickly to demand shocks. Similarly, Mayer and Somerville (2000) show that construction is less responsive to price shocks in markets with more local regulation. The fact that an inelastic housing supply in large metropolitan areas induces high price volatility is broadly consistent with the literature on housing market bubbles. According to this literature, bubbles are seen as a temporary increase in optimism about future prices; hence, in metropolitan areas where the housing supply is less elastic, demand shocks have more of an effect on price and less of an effect on new construction. In an influential paper, Glaeser et al. (2008) present a theoretical model of housing bubbles where it is postulated that housing markets with an elastic supply have fewer and shorter bubbles and smaller price increases. It is probably not a coincidence that London also scores highly in the UBS Global Real Estate Bubble Index ${ }^{3}$ (see UBS Global Real Estate Bubble Index 2018), which estimates the probability of a bubble bursting in a given metropolis at a given point in time.

\footnotetext{
${ }^{1}$ The GFCI is a ranking of the competitiveness of financial centres based on over 29,000 financial centre assessments. The ranking is an aggregate of indices from five key areas: "Business environment", "Financial sector development", "Infrastructure factors", "Human capital", "Reputation and general factors".

${ }^{2}$ The GPCI index ranks cities around the world according to a number of parameters targeted at measuring the global influence of a given city. Metropolises ranked at the top of the index have in common the fact that: i) they are headquarters of several multinational corporations, ii) they are major financial or manufacturing centres, iii) they are important laboratories of new ideas and innovation hubs in business, economics, and culture, iv) they host high quality educational institutions, including renowned universities with international student attendance and world class research facilities, v) they feature high degree of diversity in term of language, culture, religion, and ideologies.

${ }^{3}$ The UBS Global Real Estate Index gauges the risk of a property bubble according to the pattern of indicators that account for the decoupling of local prices from local incomes and rents, or indications of excessive lending and construction activity.
} 
Against this background, the main purpose of this paper is to model the cyclical behaviour of the housing market in London. We are particularly interested in investigating if the process of financial globalisation has played a role in shaping the dynamics of the real estate market. In an interesting work, Badarinza and Ramadorai (2018) find that foreign demand is an important part of the explanation for house price dynamics in London. ${ }^{4}$ Similarly, Favilukis et al. (2013) suggest that real estate in global cities constitutes a class of asset substitutes for low-yielding government bonds and it is one in which private-equity firms, investment trusts and individual investors tend to invest. Accordingly, the question we address in this paper is: Do the real estate prices at the top end of the housing market exhibit different dynamics from that of houses located in other neighbourhoods of the city? In other words, does an explicit treatment of global investment need to be accounted for when modelling the top end of London's real estate market? Similarly, Favilukis et al. (2013) suggest that real estate in global cities constitutes a class of asset substitutes for low-yielding government bonds and it is one in which private-equity firms, investment trusts and individual investors tend to invest. Accordingly, the question we address in this paper is: Do the real estate prices at the top end of the housing market exhibit different dynamics from that of houses located in other neighbourhoods of the city? If it is actually the case that the top end market constitutes a safe-haven investment linked with foreign political and economic crises, we should see different dynamics for the houses in this segment of the market from those in other neighbourhoods. In addition, a peculiarity of world cities such as London is that house price dynamics are driven by both local and global investment demand. Strong pressure on the demand side and an inelastic supply make these cities vulnerable to housing market bubbles. Accordingly, the second issue that we address in this paper is the following: How do we model the asymmetric cycles of real estate prices in global cities such as London? In other words, what kind of econometric model would best be able to capture asymmetric adjustments to house prices? Finally, the housing market dynamics in global cities are partly related to structural factors. Rapidly increasing property prices in global cities reflect the confluence of local factors (supply constraints, regulations and zoning) and global trends (the role of foreign investors; the impact of highly- and low-skilled migration from other parts of the country and abroad). The misalignment between strong demand and inelastic supply creates asymmetric cycles. However, in locations where the housing supply is not constrained, households can buy at construction costs so that, instead of growth in house prices, these areas should exhibit growth in the housing supply. Therefore, the final issue investigated in this paper is: To what extent do house price dynamics in London reflect the developments in other large cities in the UK? Answering these questions is important, since housing markets in most global cities share many of the same characteristics due to their connectedness and shared experiences of globalization (see for example Stevenson et al. 2014).

The present paper extends the existing literature in several ways. First, we contribute to the literature on modelling housing market cycles in global cities. In this paper the

\footnotetext{
${ }^{4}$ To illustrate the scale of the phenomenon Badarinza and Ramadorai (2018) use a property-level dataset for London and document that at least $85 \%$ of residential real estate purchases by foreigners in London occur through a corporation (a preferred vehicle over the period, for tax reasons) and are routed through off-shore special purpose vehicles registered in regions such as Gibraltar, Cyprus and Panama, with the effect that the ultimate source of the capital is essentially untraceable.
} 
generalised smooth transition model (GSTAR) suggested in Canepa and Zanetti Chini (2016) (and see also Zanetti Chini 2018; Canepa et al. 2020) is used to estimate house price dynamics for the sample under consideration. The authors propose a STAR-type model where the logistic smooth transition function has two parameters governing the two tails of the sigmoid function in the nonlinear component of the model. The advantage of the proposed parameterisation with respect to the ordinary smooth transition models (STAR) is that the resulting specification can model the tails of the logistic function independently and the rate of change in the left tail of the transition function can be different from the counterpart in the right tail. Using Monte Carlo simulations we show that when properly specified the GSTAR model is able to reproduce the actual characteristics of the real data such us the duration and amplitude of the cycle. Comparing the GSTAR model with other linear and nonlinear specifications, it is also found that models which allow for asymmetric adjustments according to whether prices have been rapidly rising or falling deliver better forecasts than standard linear models.

Second, we find that within the capital city, real estate located in neighbourhoods at the top-end of the market has more pronounced asymmetrical cyclical features with shorter expansion and contraction phases and deeper downturns. These findings support the view that global factors play a role in shaping housing market dynamics. Economists have long debated the role of international capital flows and financial market liberalization in explaining cycles in house prices and more generally in asset market volatility. However, the results in the literature are still controversial. Some authors support the view that international developments have placed the property sector in a wider context where major property cycles are influenced by various conditions in the international economy (see for example Srivatsa and Lee 2012; Dehesh and Pugh 2000). Other empirical studies, however, find no evidence of twoway interdependence between the property sector and the process of deregulation and the integration of diverse economies (see for example McAllister 2001).

Finally, our results show that house price series in other large cities in the UK have different characteristic features with respect to the capital city. These findings are useful since while house price dynamics at national and regional levels have been widely investigated, research at a more disaggregated level is rare. Most available empirical works investigate house price nonlinear and cyclical behaviour using data aggregated at national and regional levels. However, the housing market dynamics in world cities such as London are affected by local economic fundamentals and global factors. Strong demand pressure on the housing market (often due to large migration influx) combined with inelastic housing supply in densely built-up areas magnify exogenous shocks and make these cities prone to housing market baubles (see Hsieh and Moretti 2019). Therefore, simply assuming that the time series properties of house prices at national or regional level would also describe the features of the real estate markets in world cities is counterfactual.

The remainder of this paper is organized as follows. In Section 2 some theoretical background in relation to modelling housing market cycles is introduced. In Section 3 the modelling procedure is discussed. In Section 4 the data are described and the empirical results are presented. In Section 5 the performance of the GSTAR model is investigated along with a number of other linear and nonlinear models. In Section 6 the properties of the house price series for London are compared with those of other large 
cities in the UK. Section 7 presents some policy implications and, finally, Section 8 contains some concluding remarks.

\section{Modelling Asymmetric Cycles in Housing Markets}

Detecting and modelling asymmetry constitutes an important issue in the study of housing market fluctuations. As Sichel (1993) points out, a cycle is asymmetric if it has a phase different from the mirror image of the opposite phase. A first type of asymmetry occurs when the average duration and dynamics of the expansion and contraction phases differ. For example, the expansion period may last longer than the contraction phase, which may be steeper. A second type of asymmetry refers to deepness; it occurs when the troughs in the cycle are deeper than the peaks. Dynamic asymmetry occurs when these two examples of asymmetry are combined.

Modelling asymmetry requires nonlinear time series models because econometric models that work under the assumption of symmetry and linearity, would clearly be misspecified in the presence of asymmetry and might lead to spurious inference (see for example Blatt 1980). In the literature various nonlinear models have been used to capture the characteristics of house price series (see, among others, Kim and Bhattacharya 2009; Crawford and Fratantoni 2003; Balcilar et al. 2015). Most empirical works accommodate the departure from linearity of house price series by using a transition or switching model that captures the fact that the housing market behaves differently according to the state of the economic system. The state of the system is defined in terms of a function of a transition variable, which may be observable or unobserved. Along with the latter, the way that the system moves from one state to another (that is, the transition mechanism) needs to be specified. The choices of the transition variable and the transition mechanism have given rise to different approaches to modelling the feature under consideration (Proietti 1999). In the house price literature various nonlinear models have been used to capture the characteristics of the real estate cycle. For example, Kim and Bhattacharya (2009) use an exponential smooth transition autoregressive model (ESTAR) to model nonlinearity in the regional hosing market in the United States. Nonlinear models are also used in Crawford and Fratantoni (2003) to forecast house price changes.

Regime-switching models such as the STAR allow the dynamics of house price growth rates to evolve according to a smooth transition between regimes that depends on the signs and magnitude of past realisation of house price growth rates (see Chan and Tong 1986). The low speed of transitions between different regimes in house price growth found in empirical studies validates the choice of smooth transition models. A possible shortcoming of these types of nonlinear model describing the features of housing markets is that in the model specification a symmetric transition function is used to capture oscillations from the conditional mean of the changes in house price series. Although STAR-type models efficiently describe nonlinearity in house price growth rates, the commonly used transition functions may not be suitable for capturing dynamic asymmetries in real estate cycles. In a recent work Canepa et al. (2020) argue that the type of logistic transition function adopted in STAR models may not be the best specification to capture asymmetric oscillations from the conditional mean of house price in global cities. Modelling house price series for a number of global cities, the 
authors show that using a class of models indexed by two shape parameters that influence the symmetry and heaviness of the tails of the fitted transition equation is more suitable to fit the non-central regions of the probability function and therefore better capture the asymmetries found in the housing market cycles. The model proposed by Canepa et al. (2020) is potentially promising since the type of parametrisation of the logistic transition function allows for the expansion and contraction phases to be modelled independently. Moreover, from the methodological point of view, the simple parametrization of the logistic function used in the paper ensures the smoothness of the transition function by construction without demanding additional effort to determining what concerns identification and estimation, and it allows thus to model the two modes in the process density function. A possible shortcoming of the empirical work in Canepa et al. (2020) is that the goodness of fit of the proposed GSTAR model is not evaluated against competing model specifications. In this respect, more work should be done to investigate whether the model is able to reproduce the characteristic features of the cycle.

\section{The Econometric Model}

This section describes the econometric model that is considered in our analysis. We refer readers to the work of Canepa and Zanetti Chini (2016) for details on the dynamic asymmetric specification, see also Teräsvirta et al. (2010) for details on smooth transition models.

Let $\Delta y_{t}$ be a realization of a the house price changes (i.e. $\Delta y_{t}=y_{t}-y_{t-1}$ ) observed at $t=1-(p-1), \ldots,-1,0,1, T-1, T$. Then, the univariate process $\left\{y_{t}\right\}_{t}^{T}$ can be specified using the following model

$$
\begin{gathered}
\Delta y_{t}=\phi^{\prime} z_{t}+\theta^{\prime} z_{t} G\left(\gamma, h\left(c_{h}, s_{t}\right)\right)+\epsilon_{t}, \quad \epsilon_{t} \sim I . I . D .\left(0, \sigma^{2}\right) \\
G\left(\gamma, h\left(c_{h}, s_{t}\right)\right)=\left(1+\exp \left\{-\prod_{k=1}^{K} h\left(c_{h}, s_{t}\right)\right\}\right)^{-1}
\end{gathered}
$$

In Eqs. (1)-(2) the vectors $z_{t}=\left(1, \Delta y_{t}, \ldots, \Delta y_{t-p}\right)^{\prime}, \phi=\left(\phi_{0}, \phi_{1}, \ldots, \phi_{p}\right)^{\prime}, \theta=\left(\theta_{0}, \theta_{1}\right.$, $\left.\ldots, \theta_{p}\right)^{\prime}$ are parameter vectors. The process $\left\{\epsilon_{t}\right\}_{t}^{T}$ in Eq. (1) is assumed to be a martingale difference sequence with respect to the history of the time series up to time $t-1$, denoted as $\Omega_{t-1}=\left[\Delta y_{1-(p-a)}, \Delta y_{t-p}\right] \quad$ with $E\left(\epsilon_{t} \quad \mid \Omega_{t-1}\right)=0 \quad$ and $E\left(\epsilon_{t}^{2} \mid \Omega_{t-1}\right)=\sigma^{2}$. The expression $G\left(\widetilde{\gamma}, h\left(c_{k}, s_{t}\right)\right)$ defines the transition function, which is assumed to be continuously differentiable with respect to the scale parameters $\widetilde{\gamma}=\left(\gamma_{1}, \gamma_{2}\right)$ and bounded between 0 and 1 . Also, $G\left(\widetilde{\gamma}, h\left(c_{k}, s_{t}\right)\right)$ is continuous in the function $h\left(c_{h}, s_{t}\right)$ and $h\left(c_{h}, s_{t}\right)$ is strictly increasing in the transition variable $s_{t}$. The transition variable $s_{t}$ is assumed to be a lagged endogenous variable, that is, $s_{t}=y_{t-d}$ for a certain integer $d>0$. The parameters $c_{k} \in\{1 ; 2\}$ are the location parameters. Defining $\eta_{t}=\left(s_{t}-c\right)$ in Eq. (2) we have 


$$
h\left(\eta_{t}\right)=\left\{\begin{array}{cc}
\gamma_{1}^{-1} \exp \left(\gamma_{1}\left|\eta_{t}\right|-1\right) & \text { if } \gamma_{1}>0 \\
0 & \text { if } \gamma_{1}=0 \\
\gamma_{1}^{-1} \log \left(1-\gamma_{1}\left|\eta_{t}\right|\right) & \text { if } \gamma_{1}<0
\end{array}\right\}
$$

for $\eta_{t} \geq 0(\eta>1 / 2)$ and

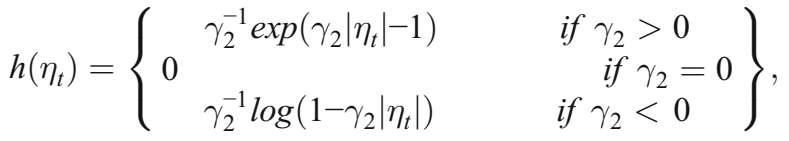

for $\eta_{t}<0(\eta>1 / 2)$.

Asymmetric behaviour in house price dynamics is introduced in the model by Eqs. (3)-(4). In particular, Eq. (3) models the higher tail of the probability function, whereas Eq. (4) models the lower tail of the probability function. The speed of the transition between the expansion and contraction regimes in the housing markets is controlled by the slope parameters $\widetilde{\gamma}$. If the vector $\widetilde{\gamma}>0$, the function $h\left(\eta_{k, t}\right)$ is an exponential rescaling which increases more quickly than a standard logistic function. On the other hand, if $\widetilde{\gamma}<0$, the function $h\left(\eta_{k, t}\right)$ is a logarithmic rescaling which increases more slowly than a standard logistic function.

Different choices of the transition function $G\left(\widetilde{\gamma}, h\left(c_{k}, s_{t}\right)\right)$ give rise to different types of regime-switching behaviour. In this paper we assume $k=1$ in Eq. (2), that is we assume that the transition function is a generalized logistic, being the literature on the topic homogeneously supportive of a logistic transition (see for example Balcilar et al. 2015). In this peculiar case, the parameters parameters on the right hand side of Eq. (1) change monotonically as a function of $s_{t}$ from $\phi$ to $\phi+\theta$ and the corresponding transition function is given by

$$
G\left(\widetilde{\gamma}, h\left(\eta_{1, t}\right)\right)=\left(1+\exp \left\{\begin{array}{c}
h\left(\eta_{1, t}\right) I_{\left(\gamma_{1 \leq 0,}, \gamma_{2 \leq 0}\right)}+h\left(\eta_{1, t}\right) I_{\left(\gamma_{1 \leq 0,}, \gamma_{2>0}\right)} \\
+h\left(\eta_{1, t}\right) I_{\left(\gamma_{1>0}, \gamma_{2 \leq 0}\right)}+h\left(\eta_{1, t}\right) I_{\left(\gamma_{1>0}, \gamma_{2>0}\right)}
\end{array}\right\}\right)^{-1}
$$

with $h\left(\eta_{1, t}\right)$ ) given in Eqs. (3)-(4) and $I(\cdot)$ is an indicator function. This parametrization can be interpreted as an endogenous shock on the vector of lagged observables that produces a change in the velocity in which the house prices passes from a lower extreme to a higher extreme. Alternative parametrizations assumes $k=2$ like the Generalized Second Order Logistic (where $c_{1}>c_{2}$ ) or the Generalized Exponential (for the case that $c_{1}=c_{2}$ ); see the ondine Appendix in Zanetti Chini (2018) for a graphical intuition of these functions. The application of these alternative transition functions on real estate data is an interesting issue that subject to future research.

The GSTAR nests several well known linear and non-linear models. For example, the model in Eq. (1) with $\gamma_{1}=\gamma_{2}=\gamma$ in the transition function in Eqs. (3)-(4) implies that the GSTAR model reduces to a one-parameter symmetric logistic STAR model (LSTAR) (see Teräsvirta et al. 2005, and Teräsvirta 1994):

$$
\left.\Delta y_{t}=\phi^{\prime} z_{t}+\theta^{\prime} z_{t} G\left(\gamma, c, s_{t}\right)\right)+\epsilon_{t}, \quad \epsilon_{t} \sim I . I . D .(0, \sigma 2)
$$


where the parameters $\phi$ and $\theta$ are previously defined and the transition variable $s_{t}$ given by

$$
G\left(\gamma, c, s_{t}\right)=\left[1+\exp \left\{\gamma-\left(s_{t}-c\right)\right\}\right]^{-1},
$$

Also, the GSTAR reduces to the model in Tong (1983) when $\widetilde{\gamma} \rightarrow+\infty$ and it becomes a straight line around $1 / 2$ for each $s_{t}$ when $\widetilde{\gamma} \rightarrow-\infty$. Finally, if $\widetilde{\gamma}$ is a null vector the GSTAR model reduces to

$$
y_{t}=\phi_{0}+\sum_{i=1}^{p} \phi_{i} z_{t-1}+\epsilon_{t}
$$

Estimating the GSTAR model involves the use of conditional least squares (COLS), that is concentrating the sum of square residuals function with respect to the vectors $\theta$ and $\phi$, that is minimizing:

$$
\operatorname{SSR}=\sum_{t=1}^{T}\left(\Delta y_{t}-\widehat{\psi}^{\prime} x_{t}^{\prime}\right)
$$

where

$$
\widehat{\psi}=[\widehat{\phi}, \widehat{\theta}]=\left(\sum_{t=1}^{T} x_{t}^{\prime}(\widetilde{\gamma}, c) x_{t}(\widetilde{\gamma}, c)\right)^{-1}\left(\sum_{t=1}^{T} x_{t}^{\prime}(\widetilde{\gamma}, c) \Delta x_{t}\right)
$$

and

$$
x_{t}(\widehat{\gamma}, \widehat{c})=\left[z_{t} z_{t}^{\prime} G\left(\widehat{\gamma}, h\left(\widehat{c}, s_{t}\right)\right)\right]
$$

Note that under the assumption that the vectors $\widetilde{\gamma}$ and $c$ are known and fixed, the GSTAR model is linear in the vectors $\theta$ and $\phi$ (see Leybourne et al. (1998). Therefore, the nonlinear least square minimization problem reduces to a minimization on three (or four) parameters and can be solved via a grid search over $\gamma_{1}, \gamma_{2}$ and $c$. In our application, both $\gamma_{1}$ and $\gamma_{2}$ are chosen between a minimum value of -10 and a maximum of 10 with an increase rate of 0.5 ; whereas the grid for the parameter $\mathrm{c}$ is the set the values computed for the range of the 10th and 90th percentile of $s_{t}$ with the increase rate computed as the difference of the two percentiles at the boundary divided by an arbitrarily high integer. The results of our empirical excercise, as well our previous experience in this maximization problems, suggest that the COLS implemented in this way works reasonably well and is at least as precise as similar conditional maximization problems for different kinds of models. See also Chan and McAleer (2002) for a discussion on the maximum likelihood methods for STAR family of models.

Before the estimated GSTAR model can be accepted as adequate, it should be subjected to misspecification tests. Some important hypotheses which should be tested 
are the hypothesis that there is no residual correlation, no remaining nonlinearity and parameter constancy (see Canepa and Zanetti Chini 2016 for more details).

\section{Data and Estimation Results}

The data under consideration are related to monthly nominal residential property prices over the period 1996:1 to 2019:9 in London. Specifically, the property price indexes published by Bloomberg are employed.

In order to investigate whether the real estate market in central London has different characteristic features from those of other neighbourhoods, we consider the property market in the central and peripheral areas separately. The London region is composed of the Greater London Authority, which includes Inner London and Outer London. Inner London is related to the Boroughs which form the interior part of Greater London, where average property prices are historically the highest in the capital, whereas Outer London relates to the group of Boroughs that form a ring around Inner London. According to the London Government Act in 1963, Outer London contains twenty Boroughs.

To investigate the housing market dynamics in different parts of the capital city we rank the twelve Boroughs of Inner London in three groups according to their average prices in the period under consideration (see Appendix Table 6 for the group classification). Following the classification of most valuation surveyors and estate agents we label these groups "super prime market", "prime market tier one" and "prime market tier two", i.e. the ranking from areas with the most valuable properties to those that are less expensive. The outer London property market is more heterogeneous than Inner London's, since it includes a minority of Boroughs with average prices close to the super prime market group, but most Boroughs feature lower average prices with respect to Inner London over the period under consideration.

Figure 1a-f plot the Kernel density function of the log house price series by urban area against a normal distribution. Looking at Fig. 1, clearly, the unconditional distributions of house price series are not normal. Overall, the estimated densities look rather a convex combination of Normal distributions with a shape that suggests two separate modes: the upper part of the distribution embodying most of the observations, and another lower part covering the lowest values of the series. Such an observation indicates that a nonlinear specification may be useful for modelling these series. However, the distributions of the Inner and Outer London prices series are quite different. This is particularly the case for the housing market in the "super prime" and "prime tier one" urban areas where negative skewness suggests deep cycles with the amplitude of the troughs exceeding that of the picks. Deepness of contractions also seems to be a characteristic feature of the housing market cycles in Outer London. However, the steepness of the cycles for real estate located in these Boroughs also appears to be an important feature since the series appear more right-skewed with respect to the Inner London neighbourhoods. This preliminary investigation, then, seems to suggest that expansions last longer than the contraction phases in Outer London. It is interesting to note that the housing market cycles in the "prime tier two" urban areas look more similar to those in Outer London than the cycles of the former urban areas located at the top end of the market. 
a)

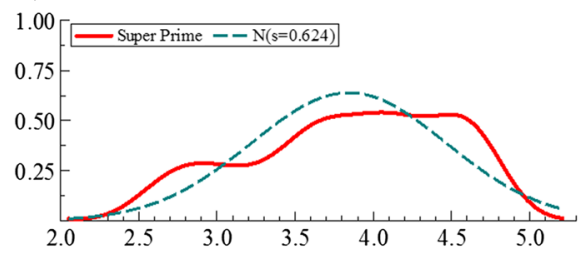

c)

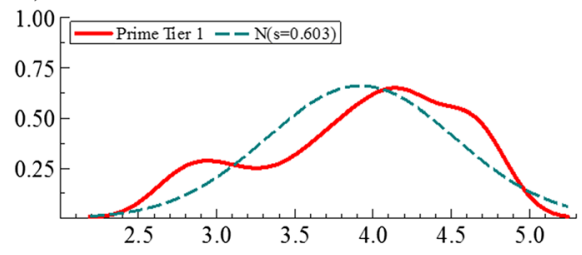

e)

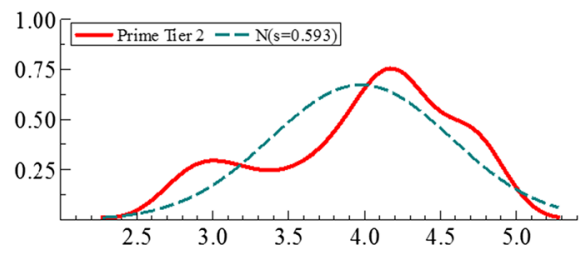

b)

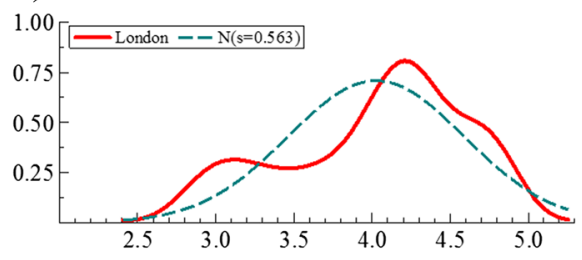

d)

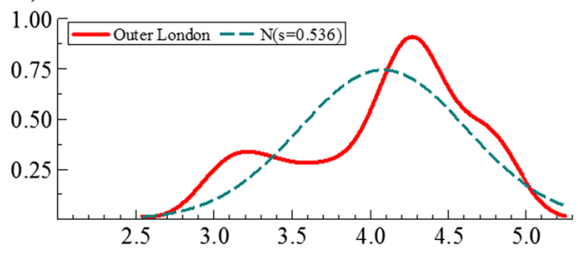

f)

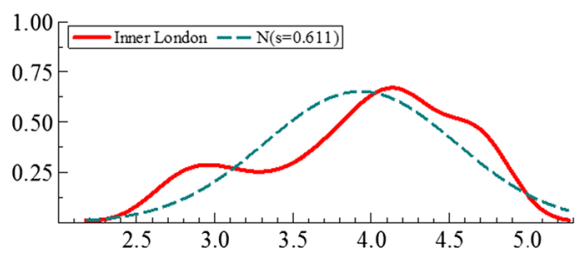

Fig. 1 a-f plot the density functions of the different series against a Normal distribution. Note that $\mathrm{s}$ denotes the standard deviation of the Normal

\section{Estimation Results}

The modelling procedure described in Section 3 involves determining the dynamic structure of the series of house price growth in the first place. In our case, for each house price series the maximal lag order of the $A R(p)$ model has been chosen by using the Bayesian information criterion and the Portmanteau test for serial correlation.

In Table 1 the estimated parameters and the relative standard errors are reported. In particular, the second column reports the estimated parameters for the series of the aggregated house price index in London, columns three to five report the estimated parameters for the "prime markets" and column six and seven report the estimated parameters for the Boroughs in Inner and Outer London .

From Table 1 it appears that house price changes are persistent since most of the estimated autoregressive coefficients, $\phi_{i}$ and $\theta_{i}$ (for $i=1, \ldots, 4$ ), are significantly different from zero. This result is consistent with the findings in Capozza et al. (2004) and Dusansky and Koç (2007) where evidence of backward-looking expectations in the housing market is found.

The estimated parameters $\gamma_{1}$ and $\gamma_{2}$ give an indication of the speed of the transition between expansion and contraction regimes, as well as the size of the cyclical peaks and troughs in the house price series for the period under consideration. Note that, these estimated coefficients are also significantly different from zero for all urban areas. With regard to the signs of these coefficients it is observed that the parameter $\gamma_{1}$ are all negative, whereas $\gamma_{2}$ are all positive. This indicates that the speed of the transition from 
Table 1 Estimation results for house price series in London

\begin{tabular}{|c|c|c|c|c|c|c|}
\hline & London & Super prime & Tier 1 & Tier 2 & Inner London & Outer London \\
\hline \multicolumn{7}{|c|}{ Estimated parameters } \\
\hline$\phi_{0}$ & $\begin{array}{l}0.666^{*} \\
(0.062)\end{array}$ & $\begin{array}{l}1.091^{*} \\
(0.073)\end{array}$ & $\begin{array}{l}0.235^{*} \\
\quad(0.021)\end{array}$ & $\begin{array}{l}0.467^{*} \\
\quad(0.080)\end{array}$ & $\begin{array}{l}0.435^{*} \\
(0.025)\end{array}$ & $\begin{array}{l}0.106^{*} \\
(0.012)\end{array}$ \\
\hline$\phi_{1}$ & $\begin{array}{l}1.799^{*} \\
(0.047)\end{array}$ & $\begin{array}{l}1.320^{*} \\
(0.028)\end{array}$ & $\begin{array}{l}1.383^{*} \\
(0.013)\end{array}$ & $\begin{array}{r}-1.053^{*} \\
(0.040)\end{array}$ & $\begin{array}{l}1.574^{*} \\
(0.023)\end{array}$ & $\begin{array}{l}1.766^{*} \\
(0.022)\end{array}$ \\
\hline$\phi_{2}$ & $\begin{array}{r}-0.856^{*} \\
(0.079)\end{array}$ & $\begin{array}{l}0.171^{*} \\
(0.039)\end{array}$ & $\begin{array}{r}-0.031 \\
(0.021)\end{array}$ & $\begin{array}{l}2.585^{*} \\
(0.096)\end{array}$ & $\begin{array}{r}-0.330^{*} \\
(0.039)\end{array}$ & $\begin{array}{r}-0.500^{*} \\
(0.044)\end{array}$ \\
\hline$\phi_{3}$ & $\begin{array}{l}0.242^{*} \\
(0.063)\end{array}$ & $\begin{array}{r}-0.785^{*} \\
(0.039)\end{array}$ & $\begin{array}{r}-0.548^{*} \\
(0.021)\end{array}$ & $\begin{array}{c}-2.510^{*} \\
(0.094)\end{array}$ & $\begin{array}{r}-0.223^{*} \\
(0.041)\end{array}$ & $\begin{array}{r}-0.448^{*} \\
(0.046)\end{array}$ \\
\hline$\phi_{4}$ & $\begin{array}{r}-0.192^{*} \\
(0.038)\end{array}$ & $\begin{array}{l}0.357^{*} \\
(0.026)\end{array}$ & $\begin{array}{l}0.168^{*} \\
\quad(0.013)\end{array}$ & $\begin{array}{l}1.088^{*} \\
(0.041)\end{array}$ & $\begin{array}{r}-0.154^{*} \\
(0.025)\end{array}$ & $\begin{array}{l}0.150^{*} \\
(0.023)\end{array}$ \\
\hline$\theta_{0}$ & $\begin{array}{r}-0.434^{*} \\
(0.130)\end{array}$ & $\begin{array}{r}-1.459^{*} \\
(0.128)\end{array}$ & $\begin{array}{r}-0.085^{*} \\
(0.035)\end{array}$ & $\begin{array}{l}0.467^{*} \\
(0.111)\end{array}$ & $\begin{array}{r}-0.353^{*} \\
(0.161)\end{array}$ & $\begin{array}{l}0.215^{*} \\
\quad(0.066)\end{array}$ \\
\hline$\theta_{1}$ & $\begin{array}{r}-1.146^{*} \\
(0.090)\end{array}$ & $\begin{array}{c}-0.350^{*} \\
(0.076)\end{array}$ & $\begin{array}{l}0.026 \\
\quad(0.065)\end{array}$ & $\begin{array}{r}-1.053^{*} \\
(0.035)\end{array}$ & $\begin{array}{r}-0.400^{*} \\
(0.107)\end{array}$ & $\begin{array}{r}-0.034^{*} \\
(0.035)\end{array}$ \\
\hline$\theta_{2}$ & $\begin{array}{l}1.746^{*} \\
(0.134)\end{array}$ & $\begin{array}{r}-0.216^{*} \\
(0.040)\end{array}$ & $\begin{array}{l}0.485^{*} \\
\quad(0.037)\end{array}$ & $\begin{array}{l}2.585^{*} \\
(0.101)\end{array}$ & $\begin{array}{r}-0.862^{*} \\
(0.093)\end{array}$ & $\begin{array}{l}0.229^{*} \\
\quad(0.075)\end{array}$ \\
\hline$\theta_{3}$ & $\begin{array}{r}-0.585^{*} \\
(0.091)\end{array}$ & $\begin{array}{l}0.428^{*} \\
(0.051)\end{array}$ & $\begin{array}{r}-0.862^{*} \\
(0.065)\end{array}$ & $\begin{array}{r}-2.510^{*} \\
(0.099)\end{array}$ & $\begin{array}{r}-0.923^{*} \\
(0.314)\end{array}$ & $\begin{array}{r}-0.454^{*} \\
(0.088)\end{array}$ \\
\hline$\theta_{4}$ & $\begin{array}{r}-0.058 \\
(0.057)\end{array}$ & $\begin{array}{r}-0.019 \\
(0.048)\end{array}$ & $\begin{array}{l}0.349^{*} \\
\quad(0.026)\end{array}$ & $\begin{array}{l}1.018^{*} \\
(0.045)\end{array}$ & $\begin{array}{l}0.473^{*} \\
(0.051)\end{array}$ & $\begin{array}{l}0.266^{*} \\
(0.047)\end{array}$ \\
\hline$\gamma_{1}$ & $\begin{array}{r}-2.950^{*} \\
(0.191)\end{array}$ & $\begin{array}{r}-7.400^{*} \\
(0.276)\end{array}$ & $\begin{array}{r}-5.400^{*} \\
(0.499)\end{array}$ & $\begin{array}{r}-0.950^{*} \\
(0.166)\end{array}$ & $\begin{array}{r}-6.900^{*} \\
(0.258)\end{array}$ & $\begin{array}{r}-1.650^{*} \\
(0.257)\end{array}$ \\
\hline$\gamma_{2}$ & $\begin{array}{l}1.204^{*} \\
(0.109)\end{array}$ & $\begin{array}{l}1.543^{*} \\
(0.291)\end{array}$ & $\begin{array}{l}1.012^{*} \\
(0.545)\end{array}$ & $\begin{array}{l}0.300^{*} \\
(0.139)\end{array}$ & $\begin{array}{l}2.451^{*} \\
\quad(0.265)\end{array}$ & $\begin{array}{l}0.592^{*} \\
(0.099)\end{array}$ \\
\hline$c$ & $\begin{array}{l}2.156^{*} \\
(0.094)\end{array}$ & $\begin{array}{l}4.422^{*} \\
\quad(0.178)\end{array}$ & $\begin{array}{l}1.018^{*} \\
(0.545)\end{array}$ & $\begin{array}{l}0.307^{*} \\
(0.025)\end{array}$ & $\begin{array}{l}5.582^{*} \\
(0.110)\end{array}$ & $\begin{array}{l}5.376^{*} \\
(0.026)\end{array}$ \\
\hline \multicolumn{7}{|c|}{ Diagnostic tests ( $p$ values) } \\
\hline $\begin{array}{c}\text { Test for } \\
\text { Corr. }\end{array}$ & 0.255 & 0.278 & 0.479 & 0.670 & 0.198 & 0.120 \\
\hline $\begin{array}{l}\text { Test for no } \\
\text { Rem. } \\
\text { Asy. }\end{array}$ & 0.556 & 0.358 & 0.706 & 0.903 & 0.862 & 0.775 \\
\hline $\begin{array}{c}\text { Test for } \\
\text { Par. } \\
\text { Const. }\end{array}$ & 0.346 & 0.382 & 0.414 & 0.385 & 0.373 & 0.350 \\
\hline
\end{tabular}

The top part of the table reports the estimated parameters for the GSTAR model and $p$-values for the misspecification tests are given in the bottom panel. The diagnostic statistics are: i) the $L M$ tests for the hypothesis that there is no serial correlation against the q-order autoregression, ii) the $L M$ test for the hypothesis that there is no remaining asymmetry, iii) the LM test for parameter constancy. Note: * and ** indicate significance level at $5 \%$ and $10 \%$, respectively

one regime to the other regime increases in periods of house price contraction at a rate greater than one which would be consistent with a standard logistic curve, but increases in the periods of house price expansion at a rate which is slower than one which would be consistent with a standard logistic function. With respect to the magnitude of the 
estimated $\gamma_{1}$ and $\gamma_{2}$ it appears that the estimated parameters for $\gamma_{1}$ are greater than $\gamma_{2}$ in modulus for all the series under consideration. This implies that, whatever the urban area, house prices in London feature a strong deep and mildly steep cycle: the house price stochastic processes undergo contraction at an accelerating pace until a given minimum, after which they start to recover with quickly decreasing acceleration until they smoothly returns to the peak, corresponding to negative skewness in the levels of the house price series.

It is interesting to note that the magnitude of the estimated parameters $\gamma_{1}$ and $\gamma_{2}$ are different in modulus for different urban areas within Inner London. In particular, the magnitude of the estimated parameters decreases as we move from the top-end market of the Super Prime to the Tier Two urban areas. This implies that the speed of transition between expansion and contraction phases is much faster for real estate located in the up-market Boroughs. At the same time, cycles are deeper in the Super Prime neighbourhoods than in Tier Two, with Tier One in between. Looking at the estimated parameters for Inner and Outer London, it appears that cycles in Inner London are, overall, deeper but shorter than in Outer London. In particular, in both urban areas house prices in expansion periods deviate from their mean at a logarithmic rate, whereas in contraction phases they return to the equilibrium level at a exponential rate. However, the magnitude of the estimated parameters also in this case indicates that the speed of transition between the expansion and contraction phases is much greater for real estate located in Inner London than Outer London. These results are certainly in line with the theoretical model in Glaeser et al. (2008) (see also Saiz 2010), where a positive correlation is postulated between population density and supply elasticity so that in high density urban areas a positive demand shock would push prices up, but would have a relatively small effect on the housing supply. However, the magnitude of the estimated parameters may also support the results described in Badarinza and Ramadorai (2018): that the top end of the London housing market is affected by international investment flows that leave the market more prone to global shocks.

Note that the relatively small estimates of $\gamma_{1}$ and $\gamma_{2}$ indicate that other types of nonlinear models in the class of regime switching, such as the Markov switching or the TAR models, are not suitable for capturing the housing market dynamics since these models assume that $\gamma_{1}=\gamma_{2} \rightarrow \infty$, thus implying a sudden transition between one regime and the next, by assumption. Coming now to the parameter $c$, this indicates the halfway point between the expansion and contraction phases of the housing markets. In Table 1 the estimated parameter $c$ is statistically significant at the $5 \%$ level.

Once the model has been estimated, we evaluate the goodness of fit of the model using the misspecification tests suggested in Canepa and Zanetti Chini (2016). In particular, the diagnostic statistics considered are: i) the LM test for the hypothesis that there is no serial correlation against the fourth order autoregression (for $q=4$ ), ii) the LM test for the hypothesis that there is no remaining asymmetry, iii) the $L M$ test for parameter constancy. The $p$ values of the tests are reported in the bottom panel of Table 1. Looking at the results of the misspecification tests it emerges that the test statistic does not reject the null hypothesis of no autocorrelation against $q$-order autoregression for all estimated models. There is also no evidence of remaining asymmetry since the $L M$ test does not reject the null hypothesis for all the estimated models. Similarly, the $L M$ test for parameter constancy does not reject the null hypothesis at the $5 \%$ significant level for all the estimated models. Overall, the results 
in Table 1 suggest that the estimated models do not suffer from misspecification problems.

\section{Dissecting London's Housing Market Cycle}

In the previous section we presented the estimation results of the GSTAR model. In this section we evaluate the properties of the model by investigating: i) whether the GSTAR model is able to replicate important features of the housing market cycle, and ii) the forecasting properties of the model.

In order to evaluate the model a useful exercise is to see what are the cycle properties the model is able to replicate when compared to the real data. This involves in the first place investigating the features of the cycle using real data to simulate the fitted model, and then comparing the outcomes to what was found when the same exercise was carried out with the actual data. Moreover, it may be of interest to compare the GSTAR to other models. We are particularly interested in investigating whether linear models can replicate the features of the housing market cycles. The investigation may be useful for highlighting the strengths and weaknesses of alternative modelling procedures. ${ }^{5}$

\section{Identifying House Price Cycles}

In order to identify house price cycles we borrow from the business cycle literature and use the Pagan and Sossounov (2003) algorithm to detect the turning points in the housing market cycle. With respect to other well-known procedures used in the literature to identify the cycle turning points (see for example Bry and Boschan 1971), the main advantage of the Pagan and Sossounov (2003) algorithm is that the data do not need to be smoothed before detecting the turning points and thus the outliers in the series do not need to be removed. This feature of the algorithm is particularly important for the data in question.

The procedure consists in finding a series of local maxima and minima that allow the series to be segmented into periods of house price expansion or contraction. The algorithm is basically a pattern-recognition program that involves finding points which are higher or lower than the window of surrounding points. Then the duration between these points is measured and a set of censoring rules is adopted which restricts the minimal lengths of any phase, as well as those of complete cycles. In particular, using a window of $j$ months, a local maximum $y_{t}$ is defined as an observation of the series such that time $t$ is a local peak if

$$
P=\left(y_{t}-y_{t-8}>0, \ldots, y_{t}-y_{t-1}>0, y_{t}-y_{t+1}>0, \ldots, y_{t}-y_{t+8}>0\right)
$$

with the inequality reversed for troughs.

\footnotetext{
${ }^{5}$ Note that below we report only the results relating to the aggregated data of the house price series in London. The analysis for the Boroughs reveals similar results. For this reason, the output is not reported, but available from the authors on request.
} 
The probability of event $P$ depends upon the joint distribution of $\left\{\Delta \ln y_{t+k}\right\}_{k=-8}^{8}$, therefore in order to calculate the probability of $P$ the specification of the data generating process (DGP) for $\Delta \ln y_{t}$ is required. The algorithm ensures that peaks and troughs alternate, so that a peak is immediately followed by a trough, and vice versa. In addition, a set of censoring rules is adopted to restrict the minimal length of any phase as well as those of complete cycles. In this paper we follow the business cycle literature (see for example Harding and Pagan 2002) and impose a censoring rule in the algorithm so that the house price cycles in each phase must last at least 6 months and complete cycles must last at least 15 months.

Once the turning points have been identified, the features of the housing market cycles can be investigated. We are particularly interested in the duration and amplitude of the cycles. In general, amplitude measures the cumulative increase (decrease) of house prices in an upturn (downturn). Duration gives an indication of the persistence of house prices; this is defined as the distance in months between a trough and a peak for expansion, whereas in case of downturns it is measured as the distance in months between a peak and a trough. The amplitude is a measure of the magnitude of the shock; it is computed as the size of the change in house prices switching from peak to trough for contraction phases and from trough to peak for expansion phases.

For ease of interpretation, following Harding and Pagan (2002), we can approximate each house price phase as a triangle where the height is the magnitude of expansion (contraction), the base is the persistence (duration) and the hypotenuse gives the path of the series for the hypothetical case of linear transition between two successive turning points. Other features of the phase can be measured by departure from the area being a triangle. In this respect, we refer to measures of the impact of a phase on the housing market as "cumulation" and "excess" measures. More precisely, cumulation is approximated by the total accumulated loss in terms of price growth as the cycle moves from peak to trough for contraction phases and vice versa for expansions. Excess, for its part is a measure which captures the deviations of house price in an expansion (contraction) phase from a triangle approximation.

Table 2 reports the average amplitude, duration, cumulation and excess for the data under consideration. The stylized facts of cycle behaviour can be summarized as follows. First, expansion phases tend to be significantly longer than contraction phases. Conversely, the amplitudes of contraction phases tend to be greater than those of expansion phases. Cumulated movements and excess cumulated movements are indicative of the shape of the cycle. The results in Table 2 imply that cumulated price increases in expansion phases are greater than those in contraction phases, probably because expansion phases on average last longer than contraction phases. Similarly, the value of the excess measures seems to point to the fact that the deviation of the contractions from a triangle approximation is greater than the deviation of the expansions.

\section{Monte Carlo Simulation Experiment}

Having established the characteristic features of the house price cycle, we now evaluate the GSTAR and other linear and nonlinear models along two different dimensions, focusing first on whether they are able to reproduce the characteristic features of the 
Table 2 Dating of peaks (troughs) in house price cycles

\begin{tabular}{lcc}
\hline & Expansion & Contraction \\
\hline Duration & 15.85 & 5.07 \\
Amplitude & 0.10 & -0.20 \\
Cumulation & 1.86 & -0.29 \\
Excess & 0.03 & -0.09 \\
\hline
\end{tabular}

The table reports the average duration in months; the average amplitude in \%; the excess from a triangle approximation

cycle described in Table 2, and then we compare these models on their ability of forecasting house prices.

The simplest data generating process (DGP) that we consider is a martingale process (RW) with mean and variance taken from house price growth. Note that a pure martingale process would produce a symmetric cycle, with contractions and expansions not significantly different in either phases of the cycle. Therefore, a martingale process would fit the hypothesis that housing markets are efficient. In the literature this hypothesis is controversial, as important theoretical works suggest that real estates are not efficient markets. This literature argues that the presence of high information costs, infrequent transactions, and the fact that houses are heterogenous products contribute to the inefficiency of housing markets (see for example Case and Shiller 1989). However, another strand of the literature contends that housing markets in large cities that feature a high volume of transactions have lower information costs per unit area than properties located in lower density urban areas have. For example, Gupta and Miller (2009) show that home prices are predictable for large metropolitan areas. Due to the relatively high transaction volume we may expect that global cities have lower information costs and a more efficient market with respect to other metropolises that do not enjoy the same status. It is therefore of interest to see to what extend a DGP drown from a martingale process is able to replicate the features of the house price series for the data at hand.

House price series are well known to have serial correlation (see Abraham and Hendershott 1993; Capozza and Seguin 1996; Malpezzi 1999; Meen 2002). In the literature the persistence in the housing market is usually referred to as the "momentum effect". Case and Shiller (1989) were the first to document momentum and predictability in housing returns. In a related study Abraham and Hendershott (1993) illustrate that persistence explain the returns in housing markets in volatile coastal cities in the United States relative to the inland cities. As Capozza et al. (2004) point out in densely populated areas high construction costs and tight regulations increase the cost of new housing and reduce the ability of builders to respond quickly to demand shocks, causing persistence in the housing market. Accordingly, the next model we consider is the $A R(p)$ model in Eq. (7) which is nested in the GSTAR.

Momentum in housing market is positively correlated to volatility (see for example Hung and Glascock 2010). To introduce heteroskedasticity in the DGP one could adopt a generating process that produces realizations of $\Delta y_{t}$ from a non-normal density. In this respect, one possibility is to change the density for $\varepsilon_{t}$ in Eq. (7) to some other density with fatter tails. However, it is more interesting to generate the excess kurtosis 
endogenously by using a GARCH-type model. In our case, a few trials in the estimation procedure revealed that the most suitable model for the data in hand was an AR-GARCH $(1,1)$. Accordingly, the AR-GARCH(1,1) model was considered. In Crawford and Fratantoni (2003) a similar model was found to fit large cities well. Finally, Alqaralleh and Canepa et al. (2020) found that the model in Eq. (6) well captured asymmetries in the housing market cycle (see also Kim and Bhattacharya 2009). Accordingly, the LSTAR model was also considered.

To compare different results we carried out a Monte Carlo experiment simulating the growth series from each of the estimated models in order to obtain the empirical density functions for each of the eight characteristics of the cycle. Details of the DGPs are given in the Appendix. We then compared these densities with the relevant characteristics in the original data and calculated the upper 5\% and the lower $95 \%$ tails of the simulated density. Then, if the calculated $p$ value of the simulated density was greater than $10 \%$, we concluded that the parametric model under consideration was unlikely to produce data with the cycle features observed in the real data.

The simulation results are reported in Table 3. For ease of interpretation the results relating to the cycle characteristic reported in Table 2 are replicated in the first row of Table 3. An asterisk next to the cycle measure indicates that the observed characteristic is outside the $90 \%$ simulated band.

Looking at the results from Table 3 it appears that the random walk model cannot reproduce cycles with peak-to-trough amplitude and cumulation similar to the actual data. Introducing the correlation in the AR(p) DGP certainly improved the fit. On the other side, modelling the conditional volatility using the $\operatorname{AR}-\operatorname{GARCH}(1,1)$ seemed to go too far, producing cycles that were too extreme, particularly in relation to the duration and amplitude of the cycle, and did little to shape the other measures accurately. Given that these models were preferred to the random walk models, such an outcome was a little unexpected, but it does serve to show that adding nonlinear structure to the conditional moments has a powerful though sometimes undesirable effect upon cycle characteristics. Looking now at the data simulated from the LSTAR data generating process, it appears that the model captures duration well, but is not

Table 3 Characteristics of expansion and contraction phases for simulated data

\begin{tabular}{|c|c|c|c|c|c|c|c|c|}
\hline \multirow[t]{2}{*}{ Model } & \multicolumn{2}{|c|}{ Duration } & \multicolumn{2}{|c|}{ Amplitude } & \multicolumn{2}{|c|}{ Cumulation } & \multicolumn{2}{|l|}{ Excess } \\
\hline & Contr. & Expan. & Contr. & Expan. & Contr. & Expan. & Contr. & Expan. \\
\hline Data & 5.07 & 15.85 & -0.20 & 0.10 & -1.86 & 0.29 & 0.03 & -0.09 \\
\hline$R W$ & 7.33 & 10.66 & -0.07 & 0.04 & -0.45 & 0.06 & 0.002 & -0.004 \\
\hline$A R(p)$ & $5.57^{*}$ & $16.14^{*}$ & -0.13 & $0.09^{*}$ & -0.95 & 0.05 & 0.004 & -0.001 \\
\hline$A R-G A R C H(1,1)$ & 10.21 & 20.42 & -0.22 & 0.31 & $-2.53^{*}$ & 0.97 & 0.006 & -0.001 \\
\hline LSTAR & $5.86^{*}$ & $16.42^{*}$ & -0.05 & $0.09^{*}$ & -10.8 & 0.20 & 0.003 & -0.01 \\
\hline GSTAR & $5.91^{*}$ & $15.20^{*}$ & $-0.22^{*}$ & $0.08^{*}$ & -1.30 & $0.33^{*}$ & $0.02^{*}$ & -0.03 \\
\hline
\end{tabular}

Note the table reports: average duration in months, amplitude in $\%$, cumulation and excess from a triangle approximation. The Table includes the $5 \%$ and $95 \%$ values of the simulated distributions of all four measures. A *) indicates that the empirical value for the London house price series data is contained in the $90 \%$ simulated confidence interval 
particularly good at replicating the other measures. These results are in line with the argument in Zanetti Chini (2018): that the logistic STAR model may be able to reproduce the steepness but not the deepness of the cycle, whereas the fact that the GSTAR model has two parameters that govern the tails of the logistic sigmoid distribution separately implies that the model outperforms its symmetric counterpart when it comes to getting the shape of the cycle right. Overall, from Table 3 it is clear that accounting for the nonlinearity observed in the data may create some extra movement with respect to the $\mathrm{AR}(\mathrm{p})$ model which is useful for replicating certain elements of the business cycle.

\section{Forecasting House Prices}

A rolling forecast experiment was implemented in order to compare the forecasting ability of the GSTAR with the other models considered in the previous section. With this target in mind the house price series was split onto two subsamples: a pre-forecast period (for $t=1, \ldots, T_{s-1}$ ) from which the model was estimated and a forecast period $t=T^{s}, \ldots, T$ with $T^{s}=t+h$. Then $h$-step-ahead forecasts were computed and compared with the pre-forecast period. The forecast period under consideration was $h=\{1,3,6$, $12\}$.

Our analysis expands beyond the traditional point forecasts to include density forecasts. Recent studies report that nonlinear models produce superior interval and density forecasts with respect to linear models, although inferior point forecasts (see, for example, Rapach and Wohar 2006). It is therefore of interest to see how the models considered in this paper compare in their predictive accuracy. Note that the RW is not considered below because the performance of the model was found in the previous section to be quite poor and therefore it could not be expected to perform well in the out-of-sample forecast exercise.

\section{Point Forecasts Measures}

We compare a linear AR $(p)$, the LSTAR and the AR-GARCH $(1,1)$ with the GSTAR model in their out-of-sample point forecasts. The out-of-sample forecast comparisons do not rely on a single criterion, for robustness we compare the results of four different measures. Namely, the mean forecast error (MFE), the root mean square forecast error (RMSFE), the symmetric mean absolute percentage error (sMAPE) and the median relative absolute error (mRAE). The four performance measures are calculated as follows:

$$
\begin{gathered}
M F E_{h}=\frac{1}{T-h-T^{s}+1} \sum_{t=T^{s}}^{T-h}\left(\Delta y_{t+h}-\Delta \widehat{y}_{t+h \mid t}\right), \\
s M A P E_{h}=\frac{100\left|\Delta y_{t+h}-\Delta \widehat{y}_{t+h}\right|}{0.5\left(\Delta y_{t+h}-\Delta \widehat{y}_{t+h \mid t}^{j}\right.},
\end{gathered}
$$




$$
\begin{gathered}
m R A E_{h}=\frac{\left|\Delta \mathrm{y}_{t+h}-\Delta \widehat{y}_{t+h}\right|}{\left|\Delta y_{t+h}-\Delta \widehat{y}_{t+h}^{1}\right|}, \text { with (1) indexing the benchmark model; } \\
R M S F E_{h}=\frac{1}{T-h-T^{S}+1} \sum_{t=T^{s}}^{T-h}\left(\Delta y_{t+h}-\Delta \widehat{y}_{t+h \mid t}\right)^{2}
\end{gathered}
$$

\section{Density Forecast Measures}

The literature on the aggregation of density forecasts focuses on the so-called scoring rules (see, for example, Geweke and Amisano 2011). These are functions that enable the forecaster to aggregate the set of conditional predictive densities. As regards point forecasting, the out-of-sample forecast comparisons based on four different scoring rules were used for aggregating the $T-T^{S}-h+1$ predictive densities produced by the same forecasting exercise:

The logarithmic score $(\operatorname{LogS})$ :

$$
\log _{j, h}=\frac{1}{T-h-T^{S}+1} \sum_{t=T^{s}}^{T-h} \log f_{t+h \mid t}^{j},
$$

which corresponds to a Kullback-Liebler distance from the true density; models with higher LogS are preferred.

The quadratic score, somewhat the equivalent of the MSFE in point forecasting, is defined as:

$$
Q R S_{j, h}=\frac{1}{T-h-T^{S}+1} \sum_{t=T^{s}}^{T-h} \sum_{k=1}^{K}\left(f_{t+h \mid t}^{j}-d_{k t}\right)^{2},
$$

where $d_{k, t}=1$ if $k=t$ and 0 otherwise; models with lower QSR are preferred.

The (aggregate) continuous-ranked probability score (CRPS), equivalent to the sMAPE, is defined as:

$$
\operatorname{CRPS}_{j, h}=\frac{1}{T-h-T^{S}+1} \times \sum_{T^{s}}^{T-h}\left(\left|f_{t-h}-f_{t+h \mid t}^{j}\right|-0.5\left|f_{t-h}-f_{t+h \mid t}^{\prime}\right|\right)
$$

where $f$ and $f^{\prime}$ are independent random draws from the predictive density and $f_{t+h \mid t}$ is the observed; models with lower CRPS are preferred.

Finally, the quantile score $(q S)$, which can be obtained if $f_{t+j \mid t}^{j}$ is replaced with a predictive $\alpha$-level quantile $q_{t+h \mid t}^{\alpha}$ in Eq. (8) (and the logarithmic function is removed); 
this score is used in risk analysis because it provides information about deviations from the true tail of the distribution.

Table 4 reports the results of the $h$-step-ahead forecasts for the forecast period $h=\{1,3,6,12\}$. In Panel A the point forecast measures are reported, whereas the density forecast performance measures are reported in Panel B. In columns 1 and 2

Table 4 Forecasting house prices: point and density predictive performances

\begin{tabular}{|c|c|c|c|c|c|}
\hline Forecast horizon & Forecast error measure & $\operatorname{AR}(p)$ & LSTAR & GSTAR & AR GARCH $(1,1)$ \\
\hline \multicolumn{6}{|c|}{ PANEL A: Point forecasts } \\
\hline 1 & MFE & 0.009 & 0.006 & 0.002 & 0.005 \\
\hline 3 & & 0.012 & 0.011 & 0.004 & 0.008 \\
\hline 6 & & 0.014 & 0.013 & 0.009 & 0.009 \\
\hline 12 & & 0.016 & 0.019 & 0.012 & 0.011 \\
\hline 1 & sMAE & 0.008 & 0.009 & 0.004 & 0.005 \\
\hline 3 & & 0.012 & 0.010 & 0.006 & 0.006 \\
\hline 6 & & 0.011 & 0.011 & 0.009 & 0.008 \\
\hline 12 & & 0.015 & 0.012 & 0.0012 & 0.010 \\
\hline 1 & mRAE & 1.000 & 1.008 & 0.995 & 0.994 \\
\hline 3 & & 1.000 & 1.012 & 1.003 & 1.004 \\
\hline 6 & & 1.000 & 1.013 & 1.005 & 1.005 \\
\hline 12 & & 1.000 & 1.023 & 1.007 & 1.007 \\
\hline 1 & RMSPE & 0.004 & 0.003 & 0.003 & 0.003 \\
\hline 3 & & 0.005 & 0.004 & 0.004 & 0.005 \\
\hline 6 & & 0.008 & 0.005 & 0.005 & 0.006 \\
\hline 12 & & 0.009 & 0.007 & 0.006 & 0.007 \\
\hline \multicolumn{6}{|c|}{ PANEL B: Density forecast } \\
\hline 1 & $\log S$ & 0.000 & 0.001 & 0.001 & 0.000 \\
\hline 3 & & 0.001 & 0.001 & 0.001 & 0.001 \\
\hline 6 & & 0.001 & 0.001 & 0.002 & 0.001 \\
\hline 12 & & 0.002 & 0.002 & 0.002 & 0.002 \\
\hline 1 & QRS & 0.003 & 0.002 & 0.002 & 0.003 \\
\hline 3 & & 0.003 & 0.003 & 0.003 & 0.004 \\
\hline 6 & & 0.004 & 0.003 & 0.003 & 0.004 \\
\hline 12 & & 0.004 & 0.004 & 0.004 & 0.005 \\
\hline 1 & CRPS & 2.051 & 1.992 & 1.877 & 1.984 \\
\hline 3 & & 2.189 & 2.078 & 1.922 & 1.994 \\
\hline 6 & & 2.452 & 2.219 & 2.004 & 2.000 \\
\hline 12 & & 2.557 & 2.267 & 2.015 & 2.002 \\
\hline 1 & $\mathrm{qS}$ & 0.021 & 0.022 & 0.021 & 0.022 \\
\hline 3 & & 0.025 & 0.026 & 0.025 & 0.024 \\
\hline 6 & & 0.037 & 0.029 & 0.034 & 0.029 \\
\hline 12 & & 0.039 & 0.037 & 0.034 & 0.034 \\
\hline
\end{tabular}

The table compares RW, AR(p), LSTAR, AR-GARCH(1,1) models and the GSTAR model in their out-ofsample forecasts. In Panel A the point forecast measures are i) the mean forecast error (MFE); ii) the root mean square forecast error (RMSFE); iii) the symmetric mean absolute percentage error (sMAPE); and iv) the median relative absolute error (mRAE). In Panel B the density forecast measures are: i) the logarithmic score (LogS) SR); iii) the continuous-ranked probability score (CRPS); and iv) the quantile score (qS). The forecast horizon is $1,3,6$ and 12 quarters 
the forecasting horizon and the forecast error measures are respectively reported, whereas in columns 3-6 the forecasting results for each model are reported. From panel A of Table 4 it is clear that, according to the point performance measures, the GSTAR model performs better than its linear and nonlinear counterparts, especially in the medium-term and long-term horizons. However, the results for the logarithmic score are mixed with the AR-GARCH $(1,1)$ occasionally outperforming the GSTAR in the long-term horizon.

Table 4 reports the results of the $h$-step-ahead forecasts for the forecast period $h=\{1,3$, $6,12\}$. In Panel A the point forecast measures are reported, whereas the density forecast performance measures are reported in Panel B. In columns 1 and 2 the forecasting horizon and the forecast error measures are respectively reported, whereas in columns 3-6 the forecasting results for each module are reported. From panel A of Table 4 it is clear that, according to the point performance measures, the GSTAR model performs better than its linear and nonlinear counterparts, especially in the medium-term and long-term horizons. However, the results for the logarithmic score are mixed with the AR-GARCH $(1,1)$ occasionally outperforming the GSTAR in the long-term horizons.

\section{Is London Different from Other Cities?}

In Section 4, the GSTAR model detected widespread evidence of asymmetric adjustment in London. Moreover, the GSTAR model revealed that, when compared to the Boroughs located in Outer London, the urban areas in Inner London feature a stronger asymmetrical cyclical component with higher upturns and deeper downturns. This result is in agreement with economic theory, where it is suggested that in large metropolitan areas the inertia of supply resulting from construction lags in combination with backward-looking expectations generates more extreme asymmetric cycles (see for example Capozza et al. 2004; Glaeser and Gyourko 2018; Case and Shiller 1989). In an influential paper, Gyourko et al. (2013) provide evidence that house prices and income growth are related. The authors give the name "superstar cities" to those metropolitan areas where: i) demand exceeds supply and ii) supply growth is limited. A crucial characteristic for a city to qualify as a superstar is that residents are willing to pay a premium to live there and the proportion of high-income households is relatively high. In places that are desirable, but have low construction rates, households with high incomes or strong preferences for this location outbid lower income families for scarce housing and drive up the price of the underlying land. By contrast, in locations where the housing supply is not constrained, households can buy at construction costs so that instead of growth in house prices, the areas exhibit growth in house supply. According to the theoretical framework suggested by Gyourko et al. (2013), the clearing process continues as long as the growth in the income-weighted demand for a location exceeds the addition in supply, either in the original location or in a close substitute. In addition to attracting highly skilled workers, global cities also attract inflows of foreign capital due to the increasing financial market liberalisation that the world has witnessed in recent years. According to Favilukis et al. (2013) (see also Badarinza and Ramadorai 2018) many countries that saw large housing booms and busts attracted foreign capital and much of this capital was invested in the property market, thanks to mortgage credit extension. 
Against this background, one question that naturally arises is: How far do the house price dynamics in London reflect the developments of other large cities in the UK? In other words, do housing markets in other large cities in the UK show similar asymmetric cyclical features?

In order to answer these questions we consider a number of large cities in UK and test whether the housing markets in these large metropolitan areas show characteristic features similar to those observed in London. With this target in mind we consider testing for nonlinearity and the dynamic asymmetry of the house price series in other large cities in the UK. To test for nonlinearity the inference procedure similar to the one suggested in Luukkonen et al. (1988) has been used. The test statistic has under the null hypothesis $H_{0}: \widetilde{\gamma}=0$ against $H_{1}: \widetilde{\gamma} \neq 0$ in Eq. (5). Therefore, if the null hypothesis is not rejected the nonlinear function $G(\cdot)$ is zero in Eq. (5). Under the null the $L M$-type test is asymptotically distributed as a $\chi 2(3 p)$ distribution. To assess whether the GSTAR model is an admissible specification with respect to the housing market cycle characteristics in these cities we also consider testing for dynamic symmetry. If the data are compatible with the GSTAR model, we saw in the previous section that, according to the results of the Monte Carlo experiment, the series generated by the model are able to reflect the characteristics of the housing market cycle.

To test for dynamic symmetry we follow Canepa and Zanetti Chini (2016) and specify the following auxiliary regression

$$
u_{t}=\widehat{z}_{1 t} \widetilde{\beta}+\sum_{j=1}^{p} \beta_{2} \Delta y_{t-j} \Delta y_{t-d}+\sum_{j=1}^{p} \beta_{3 j} \Delta y_{t-j} \Delta y_{t-d}^{2}+\sum_{j=1}^{p} \beta_{4 j} \Delta y_{t-j} \Delta y_{t-d}^{3}+v_{t},
$$

where $v_{t} \sim$ I. I. D. $(0, \sigma 2), \widetilde{\beta}_{1}=\left(\beta_{10}, \beta_{1}^{\prime}\right)^{\prime}, \beta_{10}=\phi_{0}-(c / 4) \theta_{0}, \beta_{1}=\phi-\left(\frac{c}{4}\right) \theta+\left(\frac{1}{4}\right) \theta_{0}$ $e_{d}, e_{d}=(0,0, \ldots, 1,0, \ldots, 0)^{\prime}$ with the $d$-th element equal to unit and $T_{3}(G)=f_{1} G+f_{3} G 3$ is the third-order Taylor expansion of $G(\Xi)$ at $\widetilde{\gamma}=0, f_{1}=\partial G(\Xi) /\left.\partial \Xi\right|_{\gamma=0}$ and $f_{3}=(1 / 6) \partial 3 G(\Xi) /\left.\partial \Xi\right|_{\gamma=0} G(\Xi)$ is given in the Eq. (2). To test the null hypothesis

$$
H_{0}: \beta_{2 j}=\beta_{3 j}=\beta_{4 j}=0 \quad(j=1, \ldots, p) .
$$

In Eq. (10) the following LM statistic can be used

$$
L M=\left(S S R_{0}-S S R\right) / \widehat{\sigma}_{v}^{2}
$$

where $S S R_{0}$ and $S S R$ denote the sum of the squared estimated residuals from the estimated auxiliary regression Eq. (9) and under the null and the alternative, respectively, and $\widehat{\sigma}_{v}^{2}=(1 / T) S S R$. Under the null hypothesis the LM test in Eq. (11) is asymptotically distributed as a $\chi_{p}^{2}$ distribution.

Table 5 reports the two test statistics for the ten largest cities in the UK, apart from the capital. The cities are ordered according to their population with the largest cities at the top. The top panel in Table 5 reports the $p$ values for the calculated test of nonlinearity and dynamic symmetry for London, whereas the $p$ values for the other cities are reported in the lower part of the table. 
Table 5 Linearity and dynamic symmetry tests for cities in the UK

\begin{tabular}{lcc}
\hline City & $\begin{array}{l}\text { Nonlinearity test } \\
p \text {-value }\end{array}$ & $\begin{array}{l}\text { Dynamic symmetry } \\
p \text {-value }\end{array}$ \\
\hline London & & 0.012 \\
London & 0.035 & 0.001 \\
Outer London & 0.040 & 0.050 \\
Inner London & 0.041 & \\
Other major cities & & 0.280 \\
Birmingham & 0.064 & 0.665 \\
Manchester & 0.381 & 0.114 \\
Glasgow & 0.002 & 0.613 \\
Newcastle & 0.005 & 0.672 \\
Liverpool & 0.873 & 0.643 \\
Leeds & 0.043 & 0.995 \\
Bristol & 0.338 & 0.835 \\
Belfast & 0.077 & 0.373 \\
Nottingham & 0.068 & 0.575 \\
Edinburgh & 0.034 & \\
\hline
\end{tabular}

The linearity test has under the null hypothesis that the house price series are linear. For the dynamic symmetry test the null hypothesis is dynamic symmetry and the alternative hypothesis is asymmetry. In column 1 the cities, ranked by population, are reported, whereas the tests $p$-values are reported in columns $2-3$

Looking at the results in Table 5, it appears that the characteristic features of the house price series for the largest metropolitan areas outside London are quite different from the capital city. Looking at results the null hypothesis of linearity can be rejected for the city of London, but also for many of the other large cities in the UK. On the other hand, the null hypothesis of dynamic symmetry is rejected for London, but the same is not true for all the other cities. This suggests that the characteristic of the housing markets of these cities could not be captured using a highly nonlinear specification such as the GSTAR model. Overall, the results in Table 5 suggest that the largest metropolitan areas outside London have different house price dynamics from those in the capital city.

\section{Discussion and Policy Recommendations}

The estimation results in this paper reveal several insights into the patterns of the London housing market. In particular, it is found that the expansion phases last longer than the contraction phases. This implies that house prices build up slowly in good times, but markets bust quickly when the tide changes. We also find that troughs are deeper than the peaks are tall, meaning that contractions in the housing market are more pronounced than the expansions. Looking at the house price series for major cities in the UK outside the London, it is also clear that house price movements in London are more extreme than in the rest of the country. 
Table 6 Neighbourhood classification for house prices in Inner London

Inner London Boroughs

Super Prime

Kensington and Chelsea

Westminster

Camden

City of London

Hammersmith and Fulham

Prime Tier 1

Islington

Wandsworth

Hackney

Lambeth

Prime Tier 1

Southwark

Tower Hamlets

Lewisham

Greenwich

The City of London - this is not a "Borough" as it is governed by the City of London Corporation, but is an inner London council. Since it is scarcely populated it is inserted in the "Super Prime" neighbourhoods. Note that the Boroughs are ranked by average house price with the most expansive Borough at the top

The fact that house prices in cities such as London feature asymmetric cycles has several policy implications. First, house price fluctuations in the capital region often produce spill-over effects to neighbouring regions, causing price fluctuation not justified by the fundamentals of these regions. In this respect, there is an extensive literature on the interaction of regional house prices through the "ripple effect" and how they converge or diverge over time (see for example Holmes and Grimes 2008; Cook 2006). The "ripple effect" or "price diffusion effect" is the phenomenon whereby a shock in a given housing market spreads out over time to the rest of the territory. More precisely, the ripple effect on house prices is shown as a co-movement (rise or fall) in real estate prices which affect prices in other regions in the same direction. Spatial diffusion can occur in contiguous geographical areas, but not necessarily; it may also affect discontinuous spatial territory with similar socio-economic conditions. Among other empirical works, evidence of the price diffusion effect is given in Tsay (2018) for the US, Cook and Watson (2016) for the UK, and Taltavull et al. (2017) for Spain.

Second, the recent financial crisis has made it clear that housing markets can undermine financial stability. Historical evidence shows that a significant number of banking crises were preceded by the bursting of house price bubbles (Reinhart and Rogoff 2009). Falling property prices tend to put pressure in the banking sector, not only because of the increases in mortgage default but also because of a deterioration in the balance sheets of corporate borrowers who rely on real estate as collateral. The consensus in the literature supports the view that asymmetries in housing market cycles are closely related to the credit cycle. According to this literature the over-expansion of mortgage credit in the boom phases increases leverage, building up credit risk. When the cycle turns, the impact on macroeconomic and financial stability is greatest when falling house prices and high debt interact in a downward spiral (Borio and Lowe 2002; Dell'Ariccia et al. 2012). 
Third, developments in financial markets can greatly amplify the effect of small income shocks through the economy. This is especially relevant to capital cities that are also global cities. In a seminal paper, Bernanke et al. (1996) refer to this amplification mechanism as the "financial accelerator" or "credit multiplier". The key idea behind the financial accelerator is that, under the assumption of a fixed leverage ratio, positive or negative shocks to income have a pro-cyclical effect on the borrowing capacity of households and firms. In particular, when house prices fall households have a smaller deposit (i.e. a lower loan to value ratio) available than they otherwise would for the purchase of their next home. Therefore, homeowners are able to obtain less favourable mortgage interest rates when renegotiating their mortgage and have less scope for extracting additional equity to finance consumption. A number of studies provide evidence that fluctuations in the real estate market significantly affect the value of houses as collateral and therefore strongly influence borrowing conditions for households. Claessens and Kose (2018) show that the impact of cycles on financial stability are greater the greater the dynamic asymmetry: the greater the amplitude of the fluctuations due to larger wealth effects and the longer their duration due to the fact that consumption and lending respond more strongly to persistent changes in wealth. Using a similar argument, Kiyotaki and Moore (1997) show that rising asset prices may ignite a lending boom by increasing the collateral values. A reversal in fundamentals further increases the loan default rate (see also Favilukis et al. 2017).

The behaviour of real estate markets and interaction with the financial sector and real economy have sparked a significant amount of debate among policymakers and academics regarding the appropriate policy response. Traditional tools to dampen cycles are central bank monetary policy measures targeted at managing the interest rate. It is well known that housing markets respond well to monetary policy actions, since changes to the cost of the user's capital affect the demand for residential investment (see Bernanke et al. 1996; Erceg and Levin 2006). However, monetary policy is not specifically targeted at the housing market. On the contrary, it is a general tool that affects all types of lending. Some authors have argued that the surge in interest rate required to restrain house price growth may adversely affect other sectors of the economy and increase the likelihood of a recession (see Ume 2018). In this respect, macroprudential policy targeted at limiting the uncontrolled growth of housing market credit may be more effective in damping housing market cycles. The structural macroprudential measures that could be implemented to moderate house price cycles are either borrower-based (DTI/loan-to-income/debtservice-to-income ratios, amortisation) or collateral-based (LTV) instruments. These tools have proved successful in curbing excessive house-price rises in global cities such as Hong Kong (see Gerlach and Peng 2005 among others).

Evidence of more extreme cyclical patterns in the city of London than in other regions in the UK suggests that in global cities regional tools could be used to dampen overly cyclical variation in house prices. In this respect, Cerutti et al. (2017) suggest calculating indicators that can be used by policymakers to gauge the level of overvaluation of residential housing separately for large metropolitan areas such as capital cities and for the rest of the country. This would make it possible to monitor promptly any significant developments in the property market and prevent the overheating of the market in expansion phases. In global cities the lower affordability of real estate coupled with the slower growth of household disposable income is an additional source of stronger cyclical patterns in property prices. Greater financial vulnerability could 
lead households in these cities to be more vulnerable to economic shocks, with implications for the financial stability if those households cannot repay their mortgages. In this respect regional-level tools such as local tax could be used to dampen the stronger cyclical pattern in these metropolises. Similarly, macroprudential policy measures could be regionally targeted.

Finally, it is clear that stronger cyclical patterns in large cities are partly related to structural factors. A great many studies suggest that in large metropolitan areas high real construction costs introduce unpriced supply restrictions (see for example Glaeser and Gyourko 2018; Capozza et al. 2004). In this respect, other policy measures useful for dampening the asymmetries in housing market cycles may be chosen to increase the responsiveness of the housing supply to demand shocks. Clearly, increases in the price would not occur if the housing supply was perfectly elastic. Severe supply constraints in large cities stem from a range of sources such as the availability of land and construction costs. Other important potential factors are regulatory constraints. A large volume of studies documents the likelihood that the construction costs imposed by regulation will be substantial (see, for example, Quigley and Rosenthal 2005; Zabel and Dalton 2011; Jackson 2018). In general, regulations assume different forms such as zoning, minimum lot sizes, height restrictions, open space requirements and growth controls. Other regulations, such as building codes and impact fees, can also affect the elasticity of housing supply by raising the construction costs. Measures targeted at relaxing supply restrictions may therefore help to dampen real estate cycles.

\section{Conclusion}

In this paper the generalized smooth transition model proposed in Canepa and Zanetti Chini (2016) is applied to house price series to investigate the asymmetrical behaviour of house price cycles in London. To investigate whether the GSTAR model is an admissible specification with respect to house price cycle characteristics we use Monte Carlo simulation. In particular, we use the estimated parameters to simulate the data from a GSTAR data generating process and we then use the dating approach suggested in Pagan and Sossounov (2003) to identify housing market phases and test if the GSTAR model generates time series that are able to reflect the characteristics of real estate cycles such as average durations and amplitudes of contractions and expansions, as well as other measures of the cycle shape. In this paper we also consider how the GSTAR compares with alternative models. It is found that the GSTAR model is better able to capture features of the cycle like deepness with respect to other competitive models. Finally, using different measures of point and density forecast accuracy to evaluate the performance of alternative specifications, we find that the GSTAR in most cases generates improvements in forecast performance, thus outperforming other linear and nonlinear model specifications, especially in short-term horizons.

From the methodological point of view the estimation results of the GSTAR model allow us to support most of the findings in the previous literature about the nonlinear behaviour of the housing markets in large metropolitan areas (see for example Alqaralleh and Canepa 2020; Miles 2008; Cabrera et al. 2011). However, looking at the results of the Pagan and Sossounov (2003) algorithm it is clear that the type of transition function commonly adopted in threshold models such as STAR-type models 
may be suitable for estimating house price dynamics at a higher level of aggregation (e.g. at country or regional level), but may not be the best specification to capture the asymmetric oscillations from the conditional mean of house prices for the housing market in global cities such as London. This is because house prices in these metropolises are subject to strong exogenous shocks that make the stochastic processes highly nonlinear. We find that the econometric models such as LSTAR may be able to reproduce the steepness of the cycle, but not the depth, which we found to be an important feature of the data in hand. This result may stem from the fact that STARtype models have a transition equation that is symmetric by construction. In this respect, using a class of model indexed by two shape parameters that influence the symmetry and heaviness of the tails of the fitted transition equation improves the fit of the non-central regions of the probability function and therefore the resulting model may be better able to capture the asymmetries found in the house price series.

In this paper we find that cycles in the capital feature different characteristics with respect to other large cities in the UK. This result highlights the fact that different types of econometric specification have to be used for global cities simply to reflect their different economic and social structure. Looking forward, a multivariate modification of the GSTAR that allows us to investigate spatial spillover effects would be an interesting development. Econometric models designed to calibrate the spill-over effects of regional cycles are more difficult to build than those designed for national measures, because they require additional dimensions (capturing heterogeneity between regions) and additional nonlinearities. A suitable avenue in future research would perhaps be a modelling specification for analysing house price cycles that allowed different frameworks for a capital city and for the rest of a given country.

Funding Open access funding provided by Università degli Studi di Torino within the CRUI-CARE Agreement.

\section{Appendix}

\section{Data generating processes used in the Monte Carlo experiment}

AR(3) Model:

$$
\begin{aligned}
& y_{t}=0.0019+0.212 y_{y-1}+0.263 y_{t-2}+0.254 y_{t-3}+0.124 y_{t-4}+0.010 \epsilon_{t} \\
& \begin{array}{llll}
(0.0007) & (0.063) \quad(0.062) \quad(0.063) \quad(0.031)
\end{array}
\end{aligned}
$$

LSTRAR Models:

$$
\begin{gathered}
y_{t}=-0.588+0.493 y_{t-1}-0.086 y_{t-2}-0.298 y_{t-3}-0.370 y_{t-4}+ \\
(0.070)(0.046) \quad(0.086) \\
(0.053)
\end{gathered}
$$

$-0.669 y_{t-1}-0.486 y_{t-2}+0.790 y_{t-3}-0.750 y_{t-4} \times\left[1-\exp \left(-5.374\left(y_{t-3}-0.015\right)\right)\right]^{-1}$
$(0.055)$
$(0.230)$
$(0.363)$
$(0.231)$ 
GARCH(1,1) Model:

$$
\begin{aligned}
y_{t}= & 0.004+0.478 y_{t-1}+0.010 \epsilon_{t}, \quad \text { with } \epsilon_{t} \sim N(0,1) \\
& (0.0008)(0.061)
\end{aligned}
$$

Open Access This article is licensed under a Creative Commons Attribution 4.0 International License, which permits use, sharing, adaptation, distribution and reproduction in any medium or format, as long as you give appropriate credit to the original author(s) and the source, provide a link to the Creative Commons licence, and indicate if changes were made. The images or other third party material in this article are included in the article's Creative Commons licence, unless indicated otherwise in a credit line to the material. If material is not included in the article's Creative Commons licence and your intended use is not permitted by statutory regulation or exceeds the permitted use, you will need to obtain permission directly from the copyright holder. To view a copy of this licence, visit http://creativecommons.org/licenses/by/4.0/.

\section{References}

Abraham, J.M., \& Hendershott, P.H. (1993). Patterns and determinants of metropolitan house prices (pp. 1977-1991). In L.E. Browne \& E.S. Rosengren (eds.). Real Estate and the Credit Crunch, Federal Reserve Bank of Boston.

Alqaralleh, H., \& Canepa, A. (2020). Housing market cycles in large urban areas. Economic Modelling, 92, 257-267.

Badarinza, C., \& Ramadorai, T. (2018). Home away from home? Foreign demand and London house prices. Journal of Financial Economics, 130, 532-555.

Balcilar, M., Gupta, R., \& Miller, S. M. (2015). The out-of-sample forecasting performance of non-linear models of regional housing prices in the U.S. Applied Economics, 47, 2259-2277.

Bernanke, B., Gertler, M., \& Gilchrist, S. (1996). The financial accelerator and the flight to quality. Review of Economics and Statistics, 78, 1-15.

Blatt, J. M. (1980). On the Frisch model of business cycles. Oxford Economic Papers, 32, 467-479.

Borio, C.E., \& Lowe, P.W. (2002). Asset prices, financial and monetary stability: Exploring the nexus. Bank for International Settlements Working Paper.

Bry, G., \& Boschan, C. (1971). Front matter to cyclical analysis of time series: Selected procedures and computer program. In Cyclical analysis of time series: Selected procedures and computer programs, NBER.

Cabrera, J. F., Wang, T., \& Yang, J. (2011). Linear and nonlinear predictability of international securitized real estate returns: a reality check. Journal of Real Estate Research, 33, 565-594.

Canepa, A., \& Zanetti Chini, E. (2016). Dynamic asymmetries in house price cycles: a generalized smooth transition model. Journal of Empirical Finance, 37, 91-103.

Canepa, A., Zanetti Chini, E., \& Alqaralleh, H. (2020). Global cities and local housing market cycles. Journal of Real Estate Finance and Economics, 61, 671-697.

Capozza, D. R., \& Seguin, P. J. (1996). Expectations, efficiency, and Euphoria in the housing market. Regional Science and Urban Economics, 26, 369-386.

Capozza, D. R., Hendershott, P. H., \& Mack, C. (2004). An anatomy of price dynamics in illiquid markets: analysis and evidence from local housing markets. Real Estate Economics, 32, 1-32.

Case, K. E., \& Shiller, R. J. (1989). The efficiency of the market for single-family homes. American Economic Review, 79, 125-137.

Cerutti, E., Claessens, S., \& Laeven, L. (2017). The use and effectiveness of macroprudential policies: new evidence. Journal of Financial Stability, 28, 203-224. 
Chan, F., \& McAleer, M. (2002). Maximum likelihood estimation of STAR and STAR-GARCH models: Theory and Monte Carlo evidence. Journal of Applied Econometrics, 17, 509-534.

Chan, K., \& Tong, H. (1986). On estimating thresholds in autoregressive models. Journal of Time Series Analysis, 7, 178-190.

Claessens, S., \& Kose, M.A. (2018). Frontiers of macrofinancial linkages. BIS Papers, Bank for International Settlements, 95, April.

Cook, S. (2006). A disaggregated analysis of asymmetrical behaviour in the UK housing market. Urban Studies, 43, 2067-2074.

Cook, S., \& Watson, D. (2016). A new perspective on the ripple effect in the UK housing market Comovement, cyclical subsamples and alternative indices. Urban Studies, 53, 3048-3062.

Crawford, G., \& Fratantoni, M. (2003). Assessing the forecasting performance of regime-switching, ARIMA and GARCH models of house prices. Real Estate Economics, 31, 223-243.

Dehesh, A., \& Pugh, C. (2000). Property cycles in a global economy. Urban Studies, 37, 2581-2602.

Dell'Ariccia, G., Igan, D., \& Laeven, L. (2012). Credit booms and lending standards: evidence from the subprime mortgage market. Journal of Money, Credit and Banking, 44, 367-384.

Dusansky, R., \& Koç, Ç. (2007). The capital gains effect in the demand for housing. Journal of Urban Economics, 61, 287-298.

Erceg, C., \& Levin, A. (2006). Optimal monetary policy with durable consumption goods. Journal of Monetary Economics, 53, 1341-1359.

Favilukis, J., Kohn, D., Ludvigson, S.C., \& Van Nieuwerburgh, S. (2013). International capital flows and house prices: theory and evidence. Chapter in NBER book: Housing and the financial crisis. Edward L. Glaeser and Todd Sinai, editors.

Favilukis, J., Ludvigson, S. C., \& Van Nieuwerburgh, S. (2017). The macroeconomic effects of housing wealth, housing finance, and limited risk sharing in general equilibrium. Journal of Political Economy, $125,140-223$.

Gerlach, S., \& Peng, W. (2005). Bank lending and property prices in Hong Kong. Journal of Banking and Finance, 29, 461-481.

Geweke, J., \& Amisano, G. (2011). Optimal prediction pools. Journal of Econometrics, 164, 130-141.

Glaeser, E. L., \& Gyourko, J. (2018). The economic implications of housing supply. The Journal of Economic Perspectives, 32, 3-30.

Glaeser, E. L., Gyourko, J., \& Saiz, A. (2008). Housing supply and housing bubbles. Journal of Urban Economics, 64, 198-217.

Global Power City Index (2019). Institute for Urban Strategies. The Mori Memorial Foundation.

Gupta, R., \& Miller, S. (2009). The time-series properties of house prices: A case study of the Southern California market. Journal of Real Estate Finance and Economics, 44, 339-361.

Gyourko, J., Mayer, C., \& Sinai, T. (2013). Superstar cities. American Economic Journal, 5, 167-199.

Harding, D., \& Pagan, A. (2002). Dissecting the cycle: a methodological investigation. Journal of Monetary Economics, 49, 365-381.

Holmes, M. J., \& Grimes, A. (2008). Is there long-run convergence among regional house prices in the UK? Urban Studies, 45, 1531-1544.

Hsieh, C. T., \& Moretti, E. (2019). Housing constraints and spatial misallocation. American Economic Journal: Macroeconomics, 11, 1-39.

Hung, S. Y., \& Glascock, J. (2010). Volatilities and momentum returns in real estate investment trusts. Journal of Real Estate Finance and Economics, 41, 126-149.

Jackson, K. (2018). Regulation, land constraints, and California's boom and bust. Regional Science and Urban Economics, 68, 130-147.

Kim, S., \& Bhattacharya, R. (2009). Regional housing prices in the USA: an empirical investigation of nonlinearity. Journal of Real Estate Finance and Economics, 38, 443-460.

Kiyotaki, N., \& Moore, J. (1997). Credit cycles. Journal of Political Economy, 105, 211-248.

Leybourne, S., Newbold, P., \& Vougas, D. (1998). Unit roots and smooth transitions. Journal of Time Series Analysis, 19, 83-97.

Luukkonen, R., Saikkonen, P., \& Teräsvirta, T. (1988). Testing linearity against smooth transition autoregressive models. Biometrika, 75, 491-499.

Malpezzi, S. (1999). A simple error correction model of housing prices. Journal of Housing Economics, 8, $27-62$.

Mayer, C. J., \& Somerville, C. T. (2000). Residential construction: using the urban growth model to estimate housing supply. Journal of Urban Economics, 48, 85-109.

McAllister, P. (2001). Convergence in European real estate markets: Theoretical perspectives and empirical evidence. 8th European Real Estate Society Conference. 
Meen, G. (2002). The time-series behavior of house prices: a transatlantic divide? Journal of Housing Economics, 11, 1-23.

Miles, W. (2008). Boom-bust cycles and the forecasting performance of linear and nonlinear models of house prices. Journal of Real Estate Finance and Economics, 36, 249-264.

Pagan, A. R., \& Sossounov, K. A. (2003). A simple framework for analysing bull and bear markets. Journal of Applied Econometrics, 18, 23-46.

Proietti, T. (1999). Characterising business cycle asymmetries by smooth transition structural time series models. Studies in Nonlinear Dynamics and Econometrics, 3, 141-156.

Quigley, J. M., \& Rosenthal, L. A. (2005). The effects of land use regulation on the price of housing: what do we know? What can we learn? Cityscape, 8, 69-137.

Rapach, D. E., \& Wohar, M. E. (2006). The out-of-sample forecasting performance of nonlinear models of real exchange rate behavior. International Journal of Forecasting, 22, 341-361.

Reinhart, C. M., \& Rogoff, K. S. (2009). This time is different: Eight centuries of financial folly. Princeton: Princeton University Press.

Saiz, A. (2010). The geographic determinants of housing supply. Quarterly Journal of Economics, 125, 12531296.

Sassen, S. (1991). The Global City: New York, London, Tokyo. Princeton University Press.

Sassen, S. (2003). Globalization or denationalization? Review of International Political Economy, 10, 1-22.

Sichel, D. (1993). Business cycle asymmetry: a deeper look. Economic Inquiry, 31, 224-236.

Srivatsa, R., \& Lee, S. L. (2012). European real estate market convergence. Journal of Property Investment and Finance, 30, 458-472.

Stevenson, A., Akimov, A., Hutson, E., \& Krystalogianni, A. (2014). Concordance in global office market cycles. Regional Studies, 48, 456-470.

Taltavull, P., de La Paz, A., Lopez, E., \& Juarez, F. (2017). Ripple effect on housing prices. Evidence from tourist markets in Alicante, Spain. International Journal of Strategic Property Management, 21, 1-14.

Teräsvirta, T. (1994). Specification, estimation and evaluation of smooth transition autoregressive models. Journal of the American Statistical Association, 89, 208-218.

Teräsvirta, T., Van Dijk, D., \& Medeiros, M. C. (2005). Linear models, smooth transition autoregressions, and neural networks for forecasting macroeconomic time series: a re-examination. International Journal of Forecasting, 21, 755-774.

Teräsvirta, T., Tjøstheim, D., \& Granger, C. W. J. (2010). Modelling nonlinear economic time series. Oxford: Oxford University Press.

Tong, H. (1983). Threshold models in non-linear time series analysis. No. 21 in lecture notes in statistics. Springer-Verlag, New York.

Tsay, I. C. (2018). The cause and outcomes of the ripple effect: housing prices and transaction volume. The Annals of Regional Sciences, 61, 351-373.

UBS Global Real Estate Bubble Index (2018). UBS Global Wealth Management. UBS Group AG, Zurich.

Ume, E. (2018). The impact of monetary policy on housing market activity: an assessment using sign restrictions. Economic Modelling, 68, 23-31.

Zabel, J., \& Dalton, M. (2011). The impact of minimum lot size regulations on house prices in eastern Massachusetts. Regional Science and Urban Economics, 41, 571-583.

Zanetti Chini, E. (2018). Forecasting dynamically asymmetric fluctuations of the U.S. business cycle. International Journal of Forecasting, 34, 711-732.

Publisher's Note Springer Nature remains neutral with regard to jurisdictional claims in published maps and institutional affiliations.

\section{Affiliations}

\section{Alessandra Canepa ${ }^{1,2} \cdot$ Emilio Zanetti Chini $^{3} \cdot$ Huthaifa Alqaralleh $^{4}$}

1 Department of Economic and Statistics Cognetti De Martiis, University of Turin, Lungo Dora Siena 100A, 10153 Turin, Italy

2 Department of Economics and Finance, Brunel University London, Uxbridge UB8 3PH, UK

3 Department of Economics and Law, La Sapienza University of Rome, Rome, Italy

4 Department of Economics, Business and Finance, Mutah University, Karak, Jordan 